\title{
REDESAIN KEMASAN MAKANAN RINGAN OLAHAN PADA UMKM CENTER JAWA TENGAH DENGAN METODE KANSEI ENGINEERING
}

\author{
Susatyo Nugroho ${ }^{1)}$ W, Darminto Pujotom ${ }^{2)}$, M. Mujiya Ulkhaq ${ }^{3)}$, dan Dedy Teguh \\ Permadi $^{4)}$ \\ 1) Departemen Teknik Industri, Fakultas Teknik, Universitas Diponegoro, \\ Jl. Prof. Soedarto, SH, Kampus Undip Tembalang, Semarang, Indonesia 50275 \\ ${ }^{2)}$ Departemen Teknik Industri, Fakultas Teknik, Universitas Diponegoro, \\ Jl. Prof. Soedarto, SH, Kampus Undip Tembalang, Semarang, Indonesia 50275 \\ ${ }^{3)}$ Departemen Teknik Industri, Fakultas Teknik, Universitas Diponegoro, \\ Jl. Prof. Soedarto, SH, Kampus Undip Tembalang, Semarang, Indonesia 50275 \\ 4) Departemen Teknik Industri, Fakultas Teknik, Universitas Diponegoro, \\ Jl. Prof. Soedarto, SH, Kampus Undip Tembalang, Semarang, Indonesia 50275
}

\begin{abstract}
UMKM (Micro, Small, and Medium Enterprises) Center in Central Java Province has 69 types of potential culinary products in the form of snacks. An initial study showed that from 47 MSMEs, there are 45 products which are packaged simply. The research was conducted to create a new packaging design which is appropriate for consumers' needs using Kansei Engineering. The method translates consumers' psychological feelings into new packaging design parameters as well as statistics analysis to elicit design elements in accordance with Kansei Word. Affective and psychological aspects that affect consumers on product packaging are "adorable" and "simplicity". Each component has different Kansei word variables. Adorable component has informative, modern, colorful, interesting, and distinctive variables; whereas Kansei word with the largest weight is colored with the value of 0.961 and the smallest weight is modern with the value of 0.819. Simplicity component has simple, easy-to-carry, and easy-to-open; whereas Kansei word with the largest weight is easy-to-open with the value of 0.927 and the smallest weight is simple with the value of -0.414.
\end{abstract}

Keywords: MSME's food packaging design, Kansei Engineering, Kansei Word.

\section{PENDAHULUAN}

Usaha Mikro, Kecil, dan Menengah (UMKM) merupakan salah satu sektor yang penting bagi kemajuan perekonomian negara berkembang seperti Indonesia oleh sebab itu harus didukung oleh pemerintah. Salah satu bentuk dukungan datang dari provinsi Jawa Tengah yaitu dengan menyediakan UMKM Center yang berguna untuk meningkatkan daya saing melalui penyediaan informasi dan bisnis, pendampingan usaha, fasilitas pembiayaan, pusat promosi, galeri pemasaran, dan pengembangan jaringan usaha. produk unggulan yang dijual disana terdapat 142 jenis produk dimana terdapat 69 kuliner yang berupa makanan ringan serta sisanya berupa minuman dan sembako(gula, beras, dll) yang berasal dari berbagai daerah di Jawa Tengah.

Produk-produk tersebut harus terus melakukan pengembangan secara kontinu dari berbagai aspek. Salah satu yang harus menjadi fokus pengembangan yaitu dari aspek kemasan dimana selain fungsi utamanya sebagai pelindung, kemasan juga merupakan aspek yang dapat memberikan kesan pertama kali pada konsumen sehingga memberikan stimulan kepada konsumen untuk membeli produk tersebut.

Berdasarkan latar belakang sebelumnya dibuat studi pendahuluan terhadap 90 responden pada usia 16 tahun keatas baik itu pria atau wanita yang dilakukan secara acak. Hasil studi pendahuluan menunjukkan $90 \%$ minat responden untuk membeli produk makanan olahan dipengaruhi oleh kemasannya. Sedangkan $70 \%$ responden menganggap bahwa kemasan yang ada saat ini masih kurang baik secara umum dilihat dari sisi warna, content, dan tampilan visual 
secara keseluruhan. Berdasarkan hal tersebut maka penelitian ini berfokus pada perancangan ulang desain kemasan produk makanan ringan olahan UMKM yang terdapat pada UMKM Center Jawa Tengah dengan melibatkan perasaan psikologis konsumen. Metode yang digunakan adalah Kansei Engineering, dimana metode ini merupakan metode keteknikan untuk menerjemahkan perasaan psikologis menjadi parameter desain sebuah produk (Nagamachi, 1995).

\section{METODE PENELITIAN}

Langkah-langkah yang dilakukan dalam penelitian ini sebagai berikut :

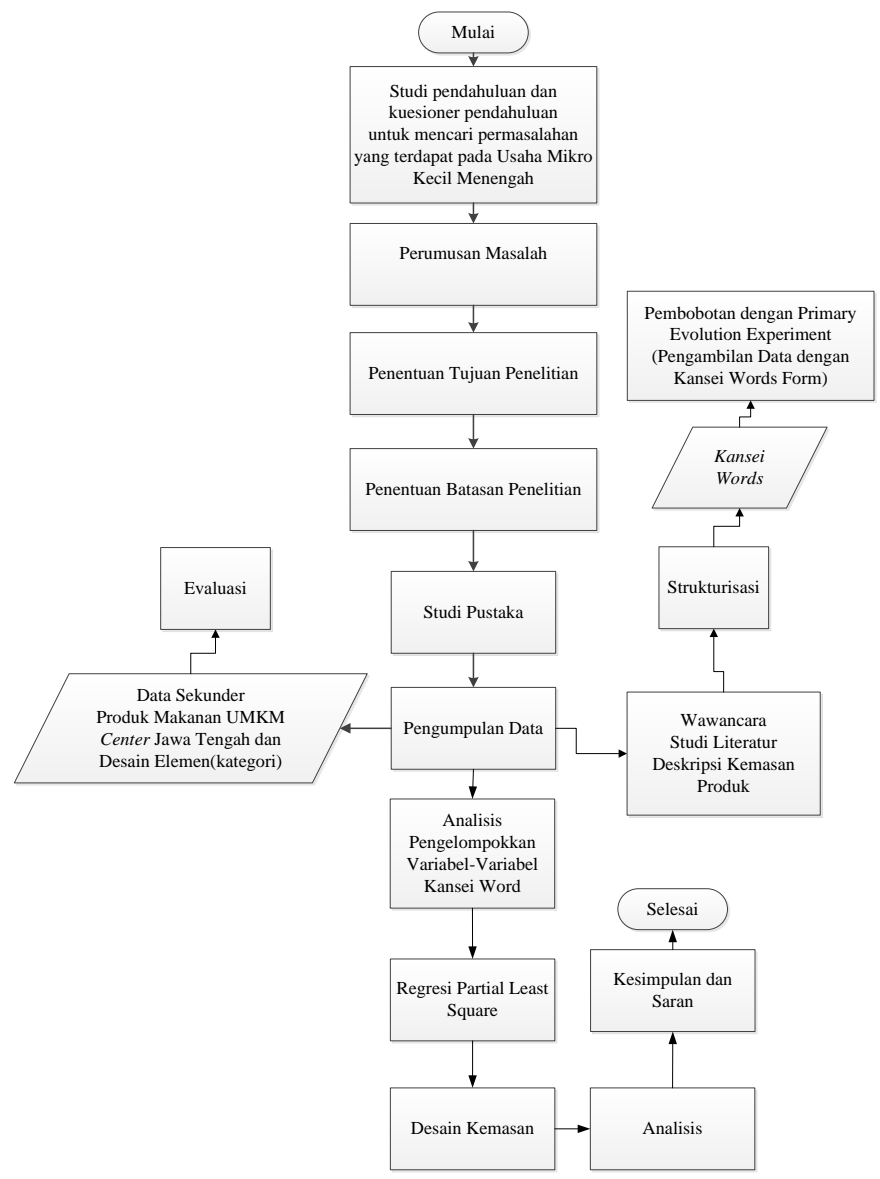

Gambar 1.Tahapan Penelitian

\section{TINJAUAN PUSTAKA}

\section{- Fungsi Kemasan}

Kemasan memiliki fungsi yang sangat penting, Setiadi (2005) memberikan beberapa prinsip bagi perancang kemasan agar memahami proses kemasan antara lain :

1 Kemasan berfungsi sebagai informasi, sehingga desain kemasan harus jujur dan memberikan informasi tentang produk. Artinya kemasan harus sesuai dengan desain yang tertera pada kemasan dengan isinya.

2 Kemasan memiliki fungsi sebagai pelindung produk serta memiliki fungsi kepraktisan yang harus sesuai dengan pandangan konsumen.

3 Kemasan memilki fungsi branding/merek sebagai sarana komunikasi citra dan posisi produk dipasar.

\section{- Variabel Kemasan}

Menurut Nillson \& Ostrom (2005) dalam Cahyorini \& Rusfian (2011), variabel desain kemasan terdiri dari 3 dimensi, yaitu: desain grafis, struktur desain, dan informasi produk. 
Desain grafis adalah dekorasi visual pada permukaan kemasan (Nilsson \& Ostrom, 2005 ) dalam Cahyorini \& Rusfian (2011), dan terdiri dari empat subdimensi, yaitu: nama merek, warna, tipografi, dan gambar.

1 Nama Merek

Asosiasi Pemasaran Amerika mendefinisikan merek (brand) sebagai nama, istilah, tanda, simbol, atau rancangan, atau kombinasi dari semuanya, yang dimaksudkan untuk mengidentifikasikannya dari barang atau jasa dari satu penjual/kelompok penjual dan mendeferensiasikan dari para pesaing (Kotler \& Keller, 2012).

2 Warna

Literatur pemasaran mengungkapkan bahwa warna kemasan memiliki kemampuan untuk membangkitkan perasaan, perilaku emosi pada konsumen yang berbeda (Mustikiwa \& Marumbwa, 2013). Warna memiliki potensi untuk menciptakan kesan yang mendalam dan tahan lama serta citra produk atau merek. Dalam kemasan produk, pemasar menggunakan warna untuk menarik perhatian konsumen yang dapat menciptakan perasaan positif atau negatif tentang produk/brand tertentu. Warna kemasan mengkomunikasikan, menggambarkan, dan menampilkan fitur-fitur yang menyolok mata serta atribut intangibel dari sebuah merek (Mustikiwa \& Marumbwa, 2013). Hal ini dengan demikian berarti bahwa warna membawa pesan khusus mengenai merek yang pada akhirnya menciptakan proposisi penjualan yang unik (unique selling proposistion).

3 Tipografi

Typography (Tipografi) merupakan suatu ilmu dalam memilih dan menata huruf dengan pengaturan penyebarannya pada ruang-ruang yang tersedia, untuk menciptakan kesan tertentu, sehingga dapat menolong pembaca untuk mendapatkan kenyamanan membaca semaksimal mungkin. Tipografi dapat juga dikatakan "visual language".

4 Gambar

Gambar (image) termasuk foto, ilustrasi, simbol/icon, dan karakter. Secara khusus gambar berfungsi pula untuk menarik perhatian, memperjelas sajian ide, mengilustrasikan/menghiasi fakta yang mungkin cepat akan dilupakan atau diabaikan tidak digambarkan (Klimchuck \& Krasovec, 2007).

b Struktur Desain

Struktur desain berkaitan dengan fitur-fitur fisik kemasan, dan terdiri dari 3 subdimensi: bentuk, ukuran, dan material.

1 Bentuk

Bentuk mempengaruhi proteksi dan fungsi keamanan dalam menyentuh, menuangkan, dan menyimpan (Smith, 1993). Sedangkan menurut Nilsson \& Ostrom (2005) dalam Cahyorini \& Rusfian (2011) menyatakan bahwa bentuk yang lebih sederhana lebih menarik dari pada yang biasanya, dan persegi panjang lebih banyak disukai dari pada kotak.

2 Ukuran

Ukuran adalah measurement yaitu cara menilai jumlah objek, waktu, atau situasi sesuai dengan aturan tertentu.

3 Material

Bahan kemasan mempengaruhi persepsi konsumen terhadap kualitas produk (Smith, 1993). Sedangkan menurut bahan kemasan dapat membangkitkan emosi dan perasaan tertentu, biasanya tanpa orang tersebut menyadarinya (Shimp, 2000).

c Informasi Produk

Salah satu fungsi kemasan adalah untuk mengkomunikasikan produk melalui Informasi yang tertera. Informasi produk dapat membantu konsumen dalam mengambil keputusan pembelian dengan lebih hati-hati (Silayoi \& Speece, 2005). Berdasarkan uraian tersebut, maka dapat dikatakan bahwa kemasan memiliki peranan cukup penting bagi suatu produk. Selain befungsing sebagai pelindung produk, kemasan juga secara tidak langsung menggambarkan jati diri produk itu sendiri. Dimensi-dimensi dari kemasan 
memiliki peran masing-masing untuk menghasilkan kemasan yang baik dan menarik, karena semakin menarik kemasan tersebut semakin menarik perhatian para konsumen.

\section{- Kansei Engineering}

Rekayasa Kansei atau Kansei Engineering merupakan suatu teknologi dalam bidang Ergonomi yang berorientasi pada pelanggan untuk pengembangan produk. Istilah Kansei berasal dari bahasa Jepang yang bisa didefinisikan sebagai perasaan psikologis manusia. Kansei dalam bahasa Jepang dapat diartikan sebagai penerjemahan dari perasaan atau selera pelanggan terhadap suatu produk. Gambar 2 menunjukkan diagram alirKansei EngineeringTipeI.

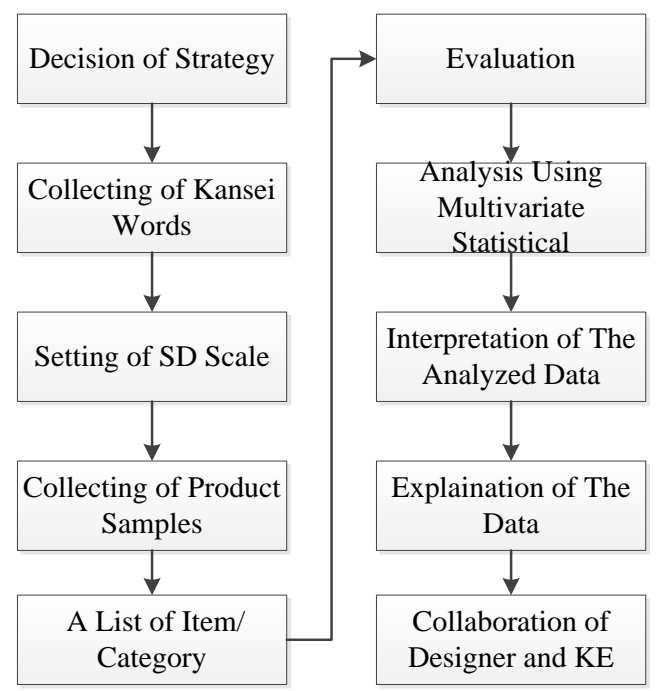

Gambar 2. Diagram AlirKansei EngineeringTipe I

\section{- Principal Component Analysis}

PCA merupakan salah satu jenis dari Analisis Faktor. Perbedaan PCA dengan Analisis Faktor pada umumnya adalah ketika tujuan dari penelitin untuk meringkas sebagian besar informasi yang asli (varians) dalam jumlah faktor yang paling minimum. Dalam perhitungannya, PCA menggunakan total varians, sedangkan Analisis Faktor hanya menggukan common varians.

\section{- Regresi Partial Least Squares}

Partial Least Square pertama kali dikembangankan pada tahun 1960-an oleh Herman O.A. Wold dalam bidang ekonometrika. PLS merupakan suatu teknik prediktif yang bisa menangani banyak variabel independen, bahkan sekalipun terjadi multikolinieritas diantara variabel-variabel tersebut (Ramzan \& Khan, 2010). PLS merupakan alternatif untuk metode analisis regresi berganda dan regresi komponen utama karena metode PLS bersifat lebih robust, artinya parameter model tidak banyak berubah ketika sampel baru diambil dari total populasi (Geladi \& Kowalski, 1996).

\section{HASIL DAN PEMBAHASAN}

Penentuan produk pada penelitian ini dilakukan dengan menggunakan Focus Group Discussion yang terdiri dari 2 pihak UMKM Center Jawa Tengah yang berkompeten terhadap produk kuliner. Focus Group Discussion dilakukan pada tanggal 14 Juni 2016 di Semarang bersama 2 orang konsultan bisnis UMKM Center Jawa Tengah. Produk yang dijadikan sampel dalam penelitian ini yaitu 8 produk.

\section{$>$ Penentuan Struktur Elemen Desain}

Penentuan struktur elemen desain pada penelitian ini berdasarkan penelitian Radoslavov \& Nikov (2014) yang berjudul "A Checklist for Kansei Assessment of Food Package".

\section{$>$ Penentuan dan Strukturisasi Kansei Word}


Pada penelitian ini untuk menentukan kansei words diambil dari penelitian terdahulu yaitu penelitian Mamaghani dkk (2014) dimana penelitian ini memiliki objek berupa botol kecap dan menggunakan metode Kansei Engineering. Serta dialog dengan 30 responden dengan usia diatas 17 tahun dengan insidental sampling, kemudian dilakukan strukturiasasi terhadap Kansei Words tersebut. Penentuan ini dikarenakan dengan usia tersebut akan mempermudah responden dalam menjawab kuesioner yang diberikan dan menurut Champion (1981) uji-uji statistik yang ada akan sangat efektif jika diterapkan pada sampel yang jumlahnya $30 \mathrm{~s} / \mathrm{d} 60$ atau dari $120 \mathrm{~s} / \mathrm{d} 250$.

Strukturisasi Kansei Word dilakukan dengan tujuan untuk memunculkan sebuah kata Kansei yang mewakili kata lainya sehingga memiliki makna dan tujuan yang sama. Proses strukturisasi ini dilakukan menggunakan Focus Group Discussion yang terdiri dari 2 konsultan bisnis UMKM Center Jawa Tengah. Focus Group Discussion ini dilakukan pada tanggal 19 Juli 2016 di Semarang. Berikut merupakan Kansei Word yang terpilih.

Tabel 1. Kansei Words yang Digunakan dan Antonim

\begin{tabular}{|c|l|}
\hline No. & \multicolumn{1}{|c|}{$\begin{array}{c}\text { Kansei Words dan kata } \\
\text { berlawanan }\end{array}$} \\
\hline 1 & Informatif - Minim Informasi \\
\hline 2 & Simpel - Kompleks \\
\hline 3 & Menarik - Membosankan \\
\hline 4 & Modern - Tradisional \\
\hline 5 & Berwarna - Polos \\
\hline 6 & Memiliki Ciri Khas - Umum \\
\hline 7 & Mudah dibawa - Sulit dibawa \\
\hline 8 & Mudah dibuka - Sulit dibuka \\
\hline
\end{tabular}

\section{- Pembobotan Kansei Words dengan Kuesioner Semantic Differential Scale}

Pembobotan dilakukan pada Kansei words yang telah didapat dengan memberikan form kuesioner berupa skala 5 Semantic Differential yang disertai foto dari setiap sampel. Dimensi ini didapat dengan memberikan lawan sifat/antonim dari setiap kansei word yang didapat sebelumnya seperti ditunjukkan pada tabel 1. Penyebaran kuesioner pada penelitian ini ditujukan kepada konsumen yang sudah pernah membeli produk makanan ringan olahan di UMKM Center Jawa Tengah. Jumlah sampel yang ditentukan sebanyak 60 responden. Gambar 3 menunjukkan hasil dari kuesioner yang sudah dilakukan.

\begin{tabular}{|c|l|c|c|c|c|c|c|c|c|c|c|}
\hline \multirow{2}{*}{ No } & \multicolumn{1}{|c|}{$\begin{array}{c}\text { Kansei } \\
\text { Word }\end{array}$} & \multicolumn{10}{|c|}{ Sampel } \\
\cline { 3 - 13 } & \multicolumn{1}{|c|}{1} & 2 & 3 & 4 & 5 & 6 & 7 & 8 & 9 & 10 \\
\hline 1 & Informatif & 3.55 & 2.78 & 3.70 & 2.55 & 2.95 & 2.18 & 2.85 & 2.70 & 2.38 & 2.43 \\
\hline 2 & Simpel & 2.02 & 2.93 & 2.22 & 2.50 & 2.27 & 2.27 & 2.43 & 2.45 & 2.33 & 2.52 \\
\hline 3 & Menarik & 3.77 & 2.58 & 3.42 & 2.37 & 3.28 & 2.28 & 2.58 & 3.33 & 2.65 & 2.78 \\
\hline 4 & Modern & 3.93 & 2.50 & 3.47 & 2.33 & 3.35 & 2.53 & 2.63 & 3.35 & 2.50 & 2.87 \\
\hline 5 & Berwarna & 3.93 & 2.38 & 3.72 & 2.98 & 3.40 & 2.30 & 2.78 & 3.02 & 2.77 & 2.67 \\
\hline 6 & Memiliki Ciri Khas & 3.95 & 2.83 & 3.55 & 2.35 & 3.58 & 2.58 & 2.87 & 3.33 & 2.67 & 2.70 \\
\hline 7 & Mudah dibawa & 2.53 & 2.50 & 2.72 & 1.90 & 2.73 & 2.37 & 2.57 & 2.68 & 2.45 & 2.52 \\
\hline 8 & Mudah dibuka & 2.97 & 2.57 & 2.37 & 2.38 & 2.77 & 2.55 & 2.68 & 2.87 & 2.62 & 2.80 \\
\hline
\end{tabular}

Gambar 3. Nilai Rata-Rata Kuesioner SD Scale

\section{- Uji Validitas dan Reabilitas}

Data dinyatakan valid jika Kansei Word yang diuji dalam kuisioner dapat menggambarkan image produk. Software yang digunakan untuk pengolahan data adalah SPSS 23. Data bisa dikatakan valid apabila nilai $\mathrm{r}$ kalkulasi $\geq \mathrm{r}$ tabel, dengan menggunakan signifikansi $5 \%$ dan dengan nilai $\mathrm{df}=60-2=58$, sehingga nilai $\mathrm{r}$ tabel yaitu sebesar 0.2542. Hasil dari uji validitas, semua variabel dinyatakan valid, dimana perhitungan e kalkulasi $\geq \mathrm{r}$ tabel.Setelah variabel dinyatakan valid, maka langkah selanjutnya melakukan tes realibilitas dengan menggunakan software SPSS 23. Variabel dinyatakan reliabel jika nilai Cronbach' Alpha lebih besar > 0.6. Berikut ini adalah gambar 4 hasil dari uji reliabilitas. 
Reliability Statistics

\begin{tabular}{|r|r|}
\hline $\begin{array}{l}\text { Cronbach's } \\
\text { Alphs }\end{array}$ & N of Items \\
\hline .932 & 8 \\
\hline
\end{tabular}

Gambar 4. Reabilitas Test

Berdasarkan pada tabel diatas nilai Cronbach's Alpha sebesar $0.932>0.6$ sehingga dikatakan kuesioner telah reliabel.

\section{- Pengujian Variabel dengan KMO dan Bartlett's Test}

Berdasarkan hasil perhitungan yang dilakukan dengan menggunakan software SPSS 23 ditunjukkan pada gambar 5. Dari tabel tersebut menunjukkan besaran nilai Barlett Test of Sphericity adalah 75.583 pada signifikan 0.000 yang berarti pada penelitian ini ada korelasi yang sangat signifikan antar variabel. Sedangkan hasil perhitungan KMO sebesar 0.699 sehingga kecukupan sampel termasuk kategori yang cukup dan dinyatakan layak untuk dianalisis lebih lanjut.

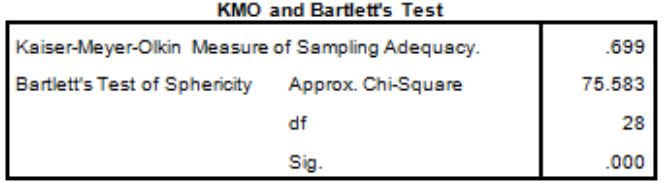

Gambar 5. KMO dan Bartlett's Test

\section{- Pengujian Anti Image Matrices}

Pengujian Anti Image matrices dilakukan untuk mengetahui apakah variabel-variabel secara parsial layak untuk dianalisis dan tidak dikeluarkan dalam pengujian. Berdasarkan gambar 6, terlihat bahwa dari 8 variabel yang akan dianalisis, nilai MSA untuk seluruh Kansei Words > 0,5 . Menunjukan bahwa komponen tersebut mempengaruhi konsumen dalam memilih suatu produk.

\begin{tabular}{|c|l|c|}
\hline No & Kansei Word & $\begin{array}{c}\text { Nilai } \\
\text { MSA }\end{array}$ \\
\hline 1 & Informatif & 0.630 \\
\hline 2 & Simpel & 0.556 \\
\hline 3 & Modern & 0.786 \\
\hline 4 & Berwarna & 0.622 \\
\hline 5 & Menarik & 0.727 \\
\hline 6 & Khas & 0.891 \\
\hline 7 & Mudahdibawa & 0.607 \\
\hline 8 & Mudahdibuka & 0.760 \\
\hline
\end{tabular}

Gambar 6. Nilai MSA

\section{- Proses Factoring}

Pada proses factoring melihat eigenvalues dari masing-masing komponen.

\begin{tabular}{|c|c|c|c|c|c|c|c|c|c|}
\hline \multirow[b]{2}{*}{ Component } & \multicolumn{3}{|c|}{ Intitial Eigenvalues } & \multicolumn{3}{|c|}{$\begin{array}{c}\text { Extraction Sums of Squared } \\
\text { Losdings }\end{array}$} & \multicolumn{3}{|c|}{$\begin{array}{c}\text { Rotation Sums of Squared } \\
\text { Losdings } 5\end{array}$} \\
\hline & Total & \begin{tabular}{|c|}
$\%$ of \\
Variance \\
\end{tabular} & \begin{tabular}{|c|} 
Cumulative \\
$\%$
\end{tabular} & Total & $\begin{array}{l}\% \text { of } \\
\text { Variance }\end{array}$ & $\begin{array}{c}\text { Cumulative } \\
\%\end{array}$ & Total & $\begin{array}{l}\text { \% of } \\
\text { Variance }\end{array}$ & $\begin{array}{c}\text { Cumulative } \\
\%\end{array}$ \\
\hline 1 & 5.644 & \begin{tabular}{|l|l|}
70.549 \\
\end{tabular} & 70.549 & 5.644 & 70.549 & 70.549 & 4.396 & 54.948 & 54.948 \\
\hline 2 & 1.112 & 13.904 & 84.453 & 1.112 & 13.904 & 84.453 & 2.360 & 29.505 & 84.453 \\
\hline 3 & .732 & 9.146 & 93.599 & & & & & & \\
\hline 4 & .371 & 4.634 & 98.233 & & & & & & \\
\hline 5 & .063 & .784 & 99.017 & & & & & & \\
\hline 6 & .046 & .571 & 99.588 & & & & & & \\
\hline $\begin{array}{l}7 \\
8\end{array}$ & .024 .009 & .295 .117 & $\begin{array}{r}99.883 \\
100.000\end{array}$ & & & & & & \\
\hline
\end{tabular}

Gambar 7. Proses Factoring

Eigenvalues berfungsi untuk mengetahui bahwa komponen akan terekstrasi ke dalam suatu faktor yang banyaknya sesuai dengan jumlah komponen yang memiliki eigenvalues > 1 tersebut. Hasil pengujian proses factoring dan matriks dapat dilihat pada gambar 7. Berdasarkan tabel tersebut terbentuk dua komponen utama yang terbentuk dari 8 variabel (Kansei Word).

\section{- Proses Pengelompokkan}

Proses ini dilakukan dengan merotasi variabel-variabel yang ada agar memperjelas variabel pembentuk komponen yang sebelumnya telah didapat. Hasil rotasi dengan menggunakan metode VARIMAX dapat dilihat pada gambar 8. 


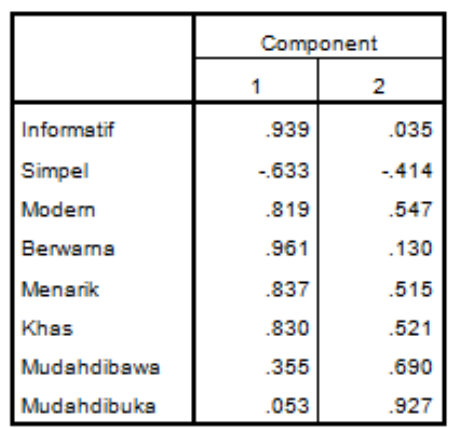

- Partial Least Square

Gambar 8. Proses Pengelompokkan

Data-data yang dilibatkan dalam analisis PLS adalah :

a Variabel y (Dependen) berupa hasil dari Principal Component Analysis.

Pada gambar 8 merupakan rata-rata bobot dari Kansei Word yang menyusun komponen baru yang terbentuk dari hasil Principal Component Analysis sebelumnya.

\begin{tabular}{|c|c|c|}
\hline Sampel & Adorable & Simplicity \\
\hline 1 & 3.83 & 2.51 \\
\hline 2 & 2.62 & 2.67 \\
\hline 3 & 3.57 & 2.43 \\
\hline 4 & 2.52 & 2.26 \\
\hline 5 & 3.31 & 2.56 \\
\hline 6 & 2.38 & 2.42 \\
\hline 7 & 2.74 & 2.56 \\
\hline 8 & 3.15 & 2.57 \\
\hline 9 & 2.59 & 2.47 \\
\hline 10 & 2.69 & 2.61 \\
\hline
\end{tabular}

Gambar 8. Rata-Rata Bobot Komponen Baru

b Variabel x (Independen) berupa elemen desain (Item)yang diterjemahkan ke dalam dummy variabel dan Sampel produk yang dalam penelitian ini berjumlah 10 .

\section{- Analisis PLS-R}

Analisis PLS-R pada penelitian ini menggunakan software xlstat 2014, hasil regresi dapat dilihat pada tabel 4.14.

\begin{tabular}{|c|l|l|l|}
\hline No & \multicolumn{1}{|c|}{ Item } & \multicolumn{1}{|c|}{ Adorable } & \multicolumn{1}{|c|}{ Simplicity } \\
\hline 1 & Bentuk & Silinder & Kotak \\
\hline 2 & Tinggi $(\mathrm{cm})$ & $27.5-31.5$ & $27.5-31.5$ \\
\hline 3 & Lebar $(\mathrm{cm})$ & $17.0-20.0$ & $17.0-20.0$ \\
\hline 4 & Tebal $(\mathrm{cm})$ & $7.0-8.0$ & $9.0-10.0$ \\
\hline 5 & Material & Plastik & Karton \\
\hline 6 & Pegangan Tambahan & Tidak ada & Tidak ada \\
\hline 7 & Penutup & Diikat & Heat Sealed \\
\hline 8 & Warna utama & Transparan & Hijau muda \\
\hline 9 & Jumlah Warna & Dua Wama & Empat Warna \\
\hline 10 & Ukuran Merek/Logo & Kecil & Besar \\
\hline 11 & Posisi Merek/Logo & Bawah & Bawah \\
\hline 12 & Ukuran Forografi Produk & Sedang & Kecil \\
\hline 13 & Posisi Fotografi Produk & Tengah & Bawah \\
\hline 14 & Ukuran Nama Produk $($ Pt) & $52-63$ & $40-51$ \\
\hline 15 & Warna Nama Produk & Merah Muda & Kuning \\
\hline 16 & Posisi Nama Produk & Atas & Atas \\
\hline 17 & Ukuran Tagline(Pt) & $14.0-17.0$ & $14.0-17.0$ \\
\hline 18 & Warna Tagline & Merah & Hitam \\
\hline 19 & Posisi Tagline & Atas & Tengah \\
\hline
\end{tabular}

Gambar 9. Hasil yang Terpilih Untuk Setiap Komponen

Terdapat besar koefisien masing-masing kategori terhadap komponoen "Adorable" dan "Simplicity". Nilai koefisien yang paling besar pada setiap Item/Category dianggap paling mewakili atau merepresentasikan komponen. Seperti pada nomor 1 item "bentuk" untuk komponen Adorable dan simplicity berturut-turut yang mimiliki nilai koefisien terbesar yaitu silinder 0.07534 dan kotak 0.02296 sehingga nantinya setiap item/category yang terpilih tersebut dijadikan acuan dalam pembuatan desain yang bisa dilihat pada gambar 9 .

\section{ANALISIS}

Desain kemasan baru merupakan desain yang terbentuk dari desain lama yang dijadikan sampel dalam penelitian ini oleh sebab itu pada desain baru memiliki beberapa unsur-unsur dari desain yang lama namun diperbarui sesuai dengan hasil penelitian yang telah dilakukan. pada 
gambar 10 dan 11 dibawah ini merupakan perbandingan antara dua desain kemasan baru "Adorable" dan desain kemasan lama.
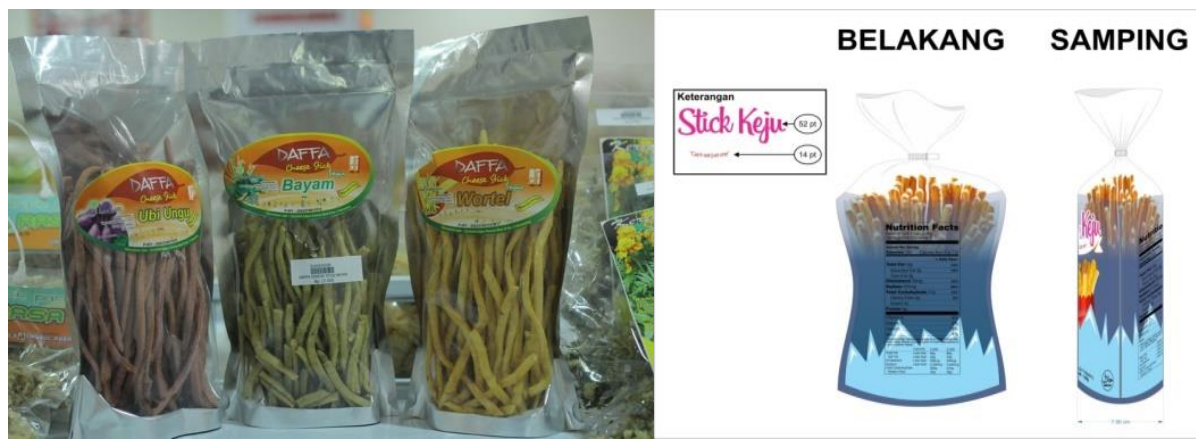

DEPAN

Gambar 10. Desain Kemasan Lama KotakGambar 11. Desain Kemasan Baru "Simplicty"

Pada gambar diatas terlihat jelas perbedaan pada desain kemasan yang baru dan lama. Meskipun demikian tetap terdapat beberapa kesamaan unsur desain seperti bentuk kemasan baru ini yang berupa silinder dengan penggabungan antara dua desain lama dengan penutup berupa ikat tembaga yang dapat mempermudah dalam membuka maupun menutup kemasan. Warna utama dari desain kemasan baru dan lama yaitu transparan namun pada desain baru terdapat dua warna tambahan yang dibuat gradasi untuk membuat kesan yang indah pada kemasan. Untuk nama produk, merek, dan tagline berbeda dengan kemasan lama. Pada desain kemasan baru ini nama produk terletak pada bagian atas dengan ukuran 52pt dan memiliki warna merah muda sehingga dapat mengkomunikasikan, menggambarkan, dan menampilkan suatu produk yang nantinya akan menciptakan kesan dan citra positif produk kepada konsumen. Posisi tagline terletak tepat dibawah nama produk dengan ukuran 14pt dan warna merah. Merek produk terletak pada bagian bawah kemasan dengan ukuran kecil namun dengan pewarnaan yang mencolok sehingga dapat mendeferensiasikan dari para pesaing atau produk lain. Pada desain kemasan lama fotografi produk memiliki bentuk serta warna yang kurang menarik sehingga pada desain kemasan baru ini untuk membuat daya tarik lebih pada produk, diberikan fotogtrafi produk berupa vektor yang diletakkan pada bagian tengah kemasan dengan ukuran sedang hal ini secara khusus berfungsi juga untuk memperjelas atau mengilustrasikan isi dari produk yang dijual. Source of Authority dan tanggal kadaluarsa memiliki posisi dibagian bawah produk dengan pewarnaan yang mencolok agar mudah terlihat hal ini dimaksudkan untuk menambah kepercayaan konsumen terhadap produk. Informasi nilai gizi pada kemasan lama dibuat secara sangat sederhana dan terkesan seadanya oleh sebab itu pada desain kemasan baru ini informasi nilai gizi ini dibuat secara jelas dan diletakkan dibagian belakang produk.

Perbedaan desain kemasan baru "simplicity" yang dapat dilihat pada gambar 5.3 dengan desain kemasan lama terlihat cukup jelas dari bentuk. Namun apabila dibandingkan bentuk desain lama yang terlihat paling mendekati desain baru ini dapat dilihat pada gambar 5.4. Bentuk desain kemasan lama yaitu kotak dengan bahan karton dan isi produk didalamnya dibungkus dengan plastik sedangkan pada desain kemasan yang baru bentuknya yaitu kotak dengan berbahan karton yang dalamnya dilapisi alumunium foil sehingga isi dari produk tidak lagi menggunakan plastik. Pada bagian atas desain yang baru memiliki arahan untuk membuka kemasan dan memiliki seal yang dapat dibuka dan ditutup kembali. Untuk warna utama pada desain kemasan yang baru dibuat lebih mencolok yaitu hijau muda dengan tambahan empat warna lainnya sedangkan pada kemasan yang lama warna terlihat lebih padam. Desain kemasan baru memiliki fotografi produk berupa vector dengan ukuran kecil yang ditempatkan pada bagian bawah sedangkan pada kemasan lama fotografi produk besar dan berupa gambar assli dari produk. Nama produk pada desain kemasan yang baru memiliki ukuran 40 pt dengan warna kuning dan latar merah yang ditempatkan pada bagian atas kemasan. Merek produk diletakkan pada bagian bawah kemasan dengan ukuran besar sedangkan pada kemasan lama ukuran merek lebih besar daripada ukuran nama produk dengan penempatan dibagian atas kemasan. Tagline pada desain kemasan baru dibuat dengan ukuran 14 pt ditempatkan pada bagian tengah dengan 
warna hitam, hal ini membuat tagline tetap terlihat mencolok dengan warna utama kemasan hijau muda. Sedangkan pada kemasan lama tidak terdapat tagline. Source of Authority dan tanggal kadaluarsa memiliki posisi dibagian bawah produk dengan pewarnaan yang mencolok agar mudah terlihat hal ini dimaksudkan untuk menambah kepercayaan konsumen terhadap produk. Informasi nilai gizi pada kemasan lama dibuat secara sangat sederhana dan terkesan seadanya oleh sebab itu pada desain kemasan baru ini informasi nilai gizi ini dibuat secara jelas dan diletakkan dibagian sisi samping kemasan.
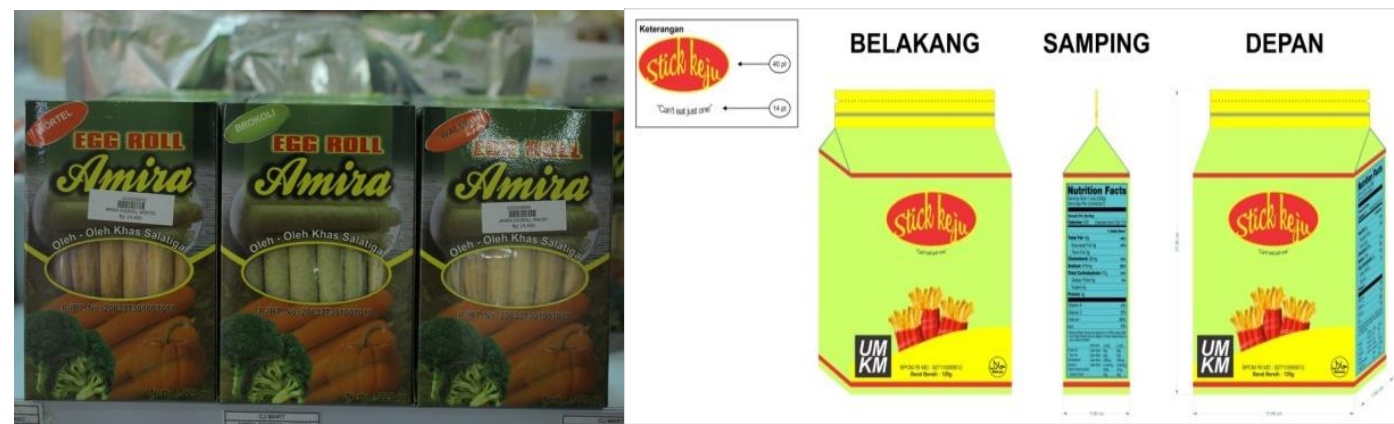

Gambar 12. Desain Kemasan Lama KotakGambar 13. Desain Kemasan Baru "Simplicty”

\section{KESIMPULAN DAN SARAN}

Berdasarkan analisis yang telah dilakukan, dapat diperoleh kesimpulan sebagai berikut:

1 Aspek afektif dan psikologis yang mempengaruhi konsumen terhadap produk kemasan produk makanan ringan olahan pada UMKM Center Jawa Tengah terbagi menjadi dua komponen yaitu komponen "Adorable" dan "Simplicity". Masing-masing dari komponen tersebut memiliki variabel-variabel kansei word yang berbeda. Pada komponen pertama "Adorable" terdapat variabel informatif, modern, berwarna, menarik, dan khas. Pada komponen pertama, kansei word dengan bobot terbesar yaitu "berwarna" dengan nilai 0.961 dan bobot terkecil yaitu "modern" dengan nilai 0.819. Pada komponen kedua "Simplicity" terdapat variabel kansei word simple, mudah dibawa, dan mudah dibuka dengan bobot terbsesar yaitu "mudah dibuka" dengan nilai 0.927 dan bobot terkecil yaitu "simple dengan nilai -0.414 .

2 Kansei words yang merepresentasikan keinginan konsumen diterjemahkan kedalam suatu usulan desain elemen dengan cara melihat korelasi antara setiap komponen yang didalamnya terdapat kansei words dengan category/item yang berupa struktur elemen desain pada kemasan sehingga menghasilkan suatu usulan tertentu.Pada usulan pertama "Adorable" didapat kemasan dengan bentuk silinder yang memiliki tinggi $27.5 \mathrm{~cm}$, tinggi $17 \mathrm{~cm}$, dan tebal $7 \mathrm{~cm}$. Material pembentuk kemasan berupa plastik dengan penutup yang diikat. Warna utama tranparan dengan total warna dua. Ukuran merek/logo kecil dan berada dibagian bawah kemasan. Ukuran fotografi produk sedang yang ditempatkan pada bagian tengah kemasan. Nama produk memiliki ukuran $52 \mathrm{Pt}$ dengan warna merah muda yang ditempatkan pada bagian atas kemasan. Ukuran tagline yaitu $14 \mathrm{Pt}$ dengan warna merah dan ditempatkan dibagian atas kemasan.Pada usulan kedua "Simplicity" didapat kemasan dengan bentuk kotak yang memiliki tinggi $27 \mathrm{~cm}$, tinggi $17 \mathrm{~cm}$, dan tebal $9 \mathrm{~cm}$. Material pembentuk kemasan berupa karton dengan penutup heat sealed. Warna utama kemasan yaitu hijau muda dengan total warna berjumlah empat warna. Ukuran merek/logo besar dan berada dibagian bawah kemasan. Ukuran fotografi produk kecil yang ditempatkan pada bagian bawah kemasan. Nama produk memiliki ukuran $40 \mathrm{Pt}$ dengan warna kuning yang ditempatkan pada bagian atas kemasan. Ukuran tagline yaitu $14 \mathrm{Pt}$ dengan warna hitam dan ditempatkan dibagian tengah kemasan. 


\section{DAFTAR PUSTAKA}

Cahyorini, \& Rusfian. (2011). The Effect of Packaging Design on Impulsive Buying. Journal of Administrative Science \& Organization, 11-21.

Champion, D. (1981). Basic Statistics For Social Research. New York: Department of Sociology, University of Tennessee.

Geladi, P., \& Kowalski, B. (1996). Partial Least Square Regression: A Tutorial. Analytica Chimica Acta, 185, 1-17.

Klimchuck, M., \& Krasovec, S. (2007). Desain Kemasan: Perencanaan Merek Produk yang Berhasil Mulai dari Konsep sampai Penjualan. Jakarta: Erlangga.

Kotler, Philip, \& Susanto, A. (2001). Manajemen Pemasaran di Indonesia. Jakarta: Salemba Empat.

Mamaghani, N. K., Rahimian, E., \& Mortezaei, S.-R. (2014). Kansei Engineering Approach for Consumer's Perception of The Ketchup Sauce Bottle. International Conference on Kansei Engineering and Emotion Research. Linkoping: KEER2014.

Mustikiwa, M., \& Marumbwa, J. (2013). The Impact of Aesthetic Package Design Elements on Consumer Purchase Intention: A Case of Locally Produced Dairy Products in Southern Zimbabwe. IOSR Journal of Business and Management, 8(5), 64-71.

Nagamachi. (1995). Kansei Engineering : A New Ergonomic Consumer Oriented Technology for Product Development. International Journal of Industrial Ergonomics, 15, 3-11.

Nilsson, Johan \& Ostrom, Tobias. (2005). Packaging as a Brand Communication Vehicle. Thesis of Lulea University of Technology.

Radoslavov, A., \& Nikov, A. (2014). A Chacklist for Kansei Assesment of Food Packages. KSI Trasactions on Knowledge Society, VII, 30-33.

Ramzan, M., \& Khan, F. (2010). Depression, Anxiety, and Their Associated Factors Among Medical Students. Journal of The College oh Physicians and Surgeons Pakistan, 20, 122-6.

Setiadi, N. (2005). Perilaku Konsumen. Jakarta: PT. Gramedia Pustaka Utama.

Silayoi, P., \& Speece, M. (2005). The Importance of Packaging Attributes: A Conjoint Analysis Approach. European Journal of Marketing, 41, 1495-1517. 